\title{
Erratum to: A methodology for controlling motion and constraint forces in holonomically constrained systems
}

\author{
Vincent De Sapio • Narayan Srinivasa
}

Published online: 17 July 2014

(C) Springer Science+Business Media Dordrecht 2014

\section{Erratum to: Multibody Syst Dyn \\ DOI 10.1007/s11044-014-9417-8}

On the opening pages of the pdf and printed versions of this article, the name of the first author Vincent De Sapio is wrongly given as De Vincent Sapio.

The online version of the original article can be found under doi:10.1007/s11044-014-9417-8.

V. De Sapio $(\varangle) \cdot$ N. Srinivasa

Information and Systems Sciences Laboratory, HRL Laboratories, LLC, Malibu, CA 90265-4797, USA

e-mail:vdesapio@hrl.com

N. Srinivasa

e-mail: nsrinivasa@hrl.com 